\title{
PREFACE
}

The 1990s are proving to be a very exciting period for high angular resolution astronomy. At radio wavelengths a combination of new array instruments and powerful imaging algorithms have generated images of unprecedented resolution and quality. In the optical and infrared, the great technical difficulties associated with constructing separated-aperture interferometers have been largely overcome, and many new instruments are now operating or are being developed. As these programs start to produce observational results they will be able to draw extensively on the experience gained by the radio-interferometry community. Thus it seemed that the time was ripe for a meeting which would bring together workers from all wavelength ranges to discuss the details of the science and art of "Very High Angular Resolution Imaging".

While the main emphasis of Symposium No. 158 was on high resolution techniques from the radio, mm-wave, infrared and optical bands, it also provided an opportunity for presentation of astronomical results from these techniques.

As well as giving our colleagues from the Northern Hemisphere a break from midwinter, the location of the Symposium in Australia recognised the continuing development of astronomical interferometry in this country, especially the recent completion of the Australia Telescope radio array, and the progress toward commissioning of the Sydney University Stellar Interferometer. A number of the participants visited these instruments during the post-symposium tour.

The Symposium was held from January 11 to 15,1993 , at the Women's College of the University of Sydney. Invited papers were given as oral presentations, and contributed papers as posters. Two panel discussions, one dealing with detectors and the other with general aspects of high resolution imaging, were held but are not included here. On 13 January a public lecture was given by Nobel Laureate Professor C H Townes, on the subject of 'Surprise and Sociology in Multi-Disciplinary Sciences'. The Editors thank Professor Townes for providing the text of this stimulating address, thus making it available to a wider audience. We are also very pleased to be able to include a contribution from Professor $\mathrm{R} \mathrm{C} \mathrm{Jennison,} \mathrm{one} \mathrm{of}$ the pioneers of the art of extracting high resolution information from interferometric data.

The Editors on behalf of the chairs of the scientific and local organizing committees would like to thank everyone associated with the Symposium for their help. While the organization was very much a team effort, we would particularly like to thank Sioe-Gek Chew for organizing the conference accommodation, Elaine Pacey for all her efforts and particularly for the success of the social program of the Symposium, Betty Siegman and Robina Otrupcek for their assistance at the Symposium desk, Andrew Booth, our long-suffering treasurer, and Doug Milne, who organized the post-Symposium tour. Finally, we thank all the participants for their contributions to the Symposium, which ensured its success.

\section{J. G. ROBERTSON}

W. J. TANGO

Editors 